\title{
A novel approach wound closure for total joint arthroplasty procedures
}

\author{
Dominick Congiusta and Fred D Cushner* \\ Chief of Orthopedics- Southside Hospital Northwell Health Orthopedic Institute, USA
}

\section{Introduction}

The importance of a successful wound closure is well known and well described in the orthopedic literature. While wound appearance is important to the patient, it is the successful healing of that surgical wound that is of utmost importance to the surgeon. An evolution has taken place over the last decade with the goal of improvement in not only the appearance of the post-operative wound, but also the elimination of wound complications.

This trend has occurred in all aspects of wound closure. For example, barbed sutures were introduced as an attempt to control the post-operative hemarthrosis often seen in the post-operative period and have demonstrated effective, water-tight closure. The importance of a water-tight closure is recognized in the literature, as are the potential complications if it is not obtained and extended wound drainage occurs [1-4]. Wound drainage has been associated with periprosthetic joint infection, morbidity, mortality, length of stay, and wound complications $[5,6]$.These complications are usually treated with absorbent dressings, temporary joint immobilization, or surgical treatment such as debridement, irrigation, and antimicrobial agent application, placing a costly burden on patients and the healthcare system [4].

The barbed suture offers the theoretical advantage of creating a more even distribution of tension across the wound. It has become popular in orthopedic surgery due to the perception that it can shorten total operative time while maintaining similar rates of infection [7]. Nett et al reported superior water-tightness using barbed sutures compared to the standard interrupted technique (with fluid leakage of $174 \mathrm{ml}$ vs. 601 $\mathrm{ml}$ on average, respectively) [8]. Several studies report on the shorter closure time with the use of barbed sutures $[9,10]$, but a 2014 metaanalysis found a lower superficial infection rate with standard sutures [11]. It has been suggested that the increased surface area of barbed sutures may provide larger surfaces for bacterial proliferation and nidi for infection $[12,13]$.

While surgical staples have long been the gold standard for wound closure, increased superficial infections have been described with their use. Some evidence shows that there may be no difference or superior outcomes when using staples in a variety of specialties [14-16], but others report increased rates of complications. Ando et al showed increased rates of wound infections with patients receiving staples $(8.0$ $\%)$ compared to those receiving sutures $(0 \%)$ in spinal surgery, and the majority of the infections in the staples group were deep infections [17]. Smith et al. [18] report a meta-analysis on closure technique used on orthopedic patients; data from six studies, consisting of 683 orthopedic procedures, showed that the risk of infection was more than three times higher when staples were used (relative risk 3.83, $95 \%$ confidence interval 1.38 to 10.68 ). On subgroup analysis of hip surgery alone, the authors found the risk of infection was over four times greater when staples were used (relative risk 4.79, $95 \%$ confidence interval 1.24 to 18.47). However, no difference was seen in rates of inflammation, discharge, dehiscence, necrosis, or allergic reaction in the same study. There is considerable heterogeneity between these studies, and a clear answer to the optimal approach to wound closure has not been established. Due to these potential complications, the search continues for improved wound closure techniques that are efficacious as well as cosmetically pleasing to the patient.

ClozeX $\mathrm{X}^{\circ}$ is an FDA approved medical device with well-established effectiveness in over 10,000 surgical procedures [19]. This new technology utilizes an interlaced design to rapidly apply tension along incision lines and secure wound closure. In practice, this technique provides shorter closure times and improved or similar outcomes to closure by conventional means.

The ClozeX ${ }^{*}$ system is recommended for low-to medium-tension surgical wounds, or as an adjunct to high tension wounds closed with conventional methods [19]. It is not recommended for areas of skin with excess fluids, oils, or hair, which render poor surfaces for adhesion of the ClozeX ${ }^{\circ}$ system. It is also not recommended for use on infected areas due to the potential risk for device failure.

\section{The technique}

At the conclusion of surgery, deep tissue layers are closed in the conventional manner. The subcutaneous tissue is also closed in either a running or interrupted fashion based on surgeon preference. The author prefers a running stitch to further enhance the watertight properties of the wound. Prior to skin closure, the ClozeX device is selected by first choosing the appropriate size to match the length of the wound. There are 11 different sizes, ranging from the long and narrow $3 / 8 "(10 \mathrm{~mm})$ to the squarer shaped $4 "(100 \mathrm{~mm})$. If a large wound must be closed, as with long surgical incisions, multiple ClozeX devices may be combined at the time of application. This may also be done for incisions on irregular or contoured surfaces, such as those with multiple skin folds. For example, for a typical Total Knee Arthroplasty (TKA) wound, 3 or 4 of the $40 \mathrm{~mm}^{\text {ClozeX }}{ }^{\circ}$ devices would be utilized.

${ }^{\star}$ Correspondence to: Fred D Cushner, Chief of Orthopedics- Southside Hospital Northwell Health Orthopedic Institute, USA, Tel: 631-647-3800, E-mail: fcush@ att.net

Received: October 25, 2018; Accepted: November 09, 2018; Published: November 13, 2018 
The skin is cleaned prior to application of the film. All debris, exudates, and oils are effectively removed from an area of 5-7 cm around the incision. The area is then dried to ensure proper adhesion of the film.

The film's adhesive portions are covered with numbered protective liners $(1,2,3)$, which help facilitate liner removal and device application. "Liner 1 " is first taken off to expose the adhesive pads. While holding the two "Liner 2s" on either side, the film is applied 1-2 mm from each side of the wound edge with the adhesive surface applied on the skin. Each Liner 2 is removed gently in succession and each pad is pressed to secure it firmly on both sides of the wound. The pull tabs are then lifted in either hand, and the two Liner 3 s are removed to secure the adhesive straps. The tabs are pulled in opposite directions to close the wound gently and uniformly. This provides excellent $3 \mathrm{D}$ control of the skin edges. When the skin edges are properly aligned under tension, the straps are lowered onto the adhesive pads below. Finally, the pulled tabs are easily removed along a perforated line (Figures 1 and 2).

The film is never lifted or reapplied once it touches the skin. If erroneously placed, a new film should be used.

\section{Discussion}

Over the last decade, new techniques have been described to aid in the final layer of wound closure. In an attempt to produce superior outcomes, devices such as Dermabond', Dermabond" Prineo, the Zip Skin Closure System, and ClozeX" have been developed.

Dermabond is a topical skin adhesive used to augment tensile strength to deep dermal sutures and provide a barrier to surgical wounds. It is composed of a 2-octyl cranoacrylate (2-OCA) liquid that forms a protective glue on incision sites. Daykan et al. [20] recently conducted a randomized trial and reported similar outcomes between Dermabond $^{\circ}$ and monofilament epidermal sutures in cesarean procedures, including length of stay, closure time, closure appearance, blood loss, infections, and wound disruption. Martin et al. [20] found no difference between cosmetic outcomes after closure with Dermabond ${ }^{\circ}$ and subcuticular sutures, although mean operative time was shorter in the Dermabond group (1.4 minutes vs. 8.6 minutes) [21].

The Dermabond ${ }^{\circ}$ Prineo skin closure system utilizes the same 2-OCA technology along with a self-adhering mesh. This system has

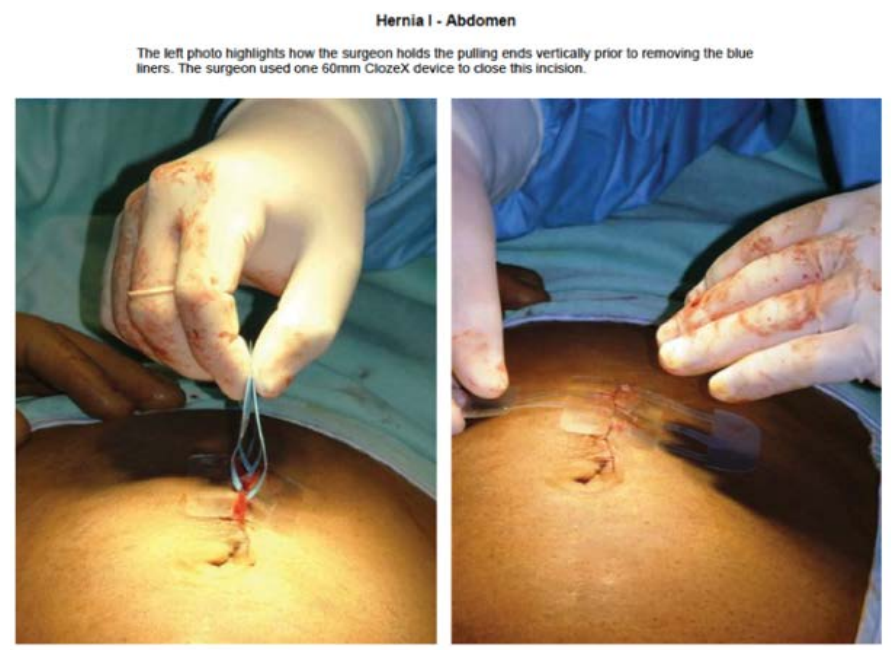

Figure 1. Application of the ClozeX ${ }^{\circledR}$ System ${ }^{\mathrm{a}}$

${ }^{\mathrm{a}}$ ClozeX ${ }^{\circledR}$ Medical Inc, Wellesley, MA
Hernia II - Abdomen

The surgeon performed this hernia closure using two ClozeX devices with no subcutaneous sutures.
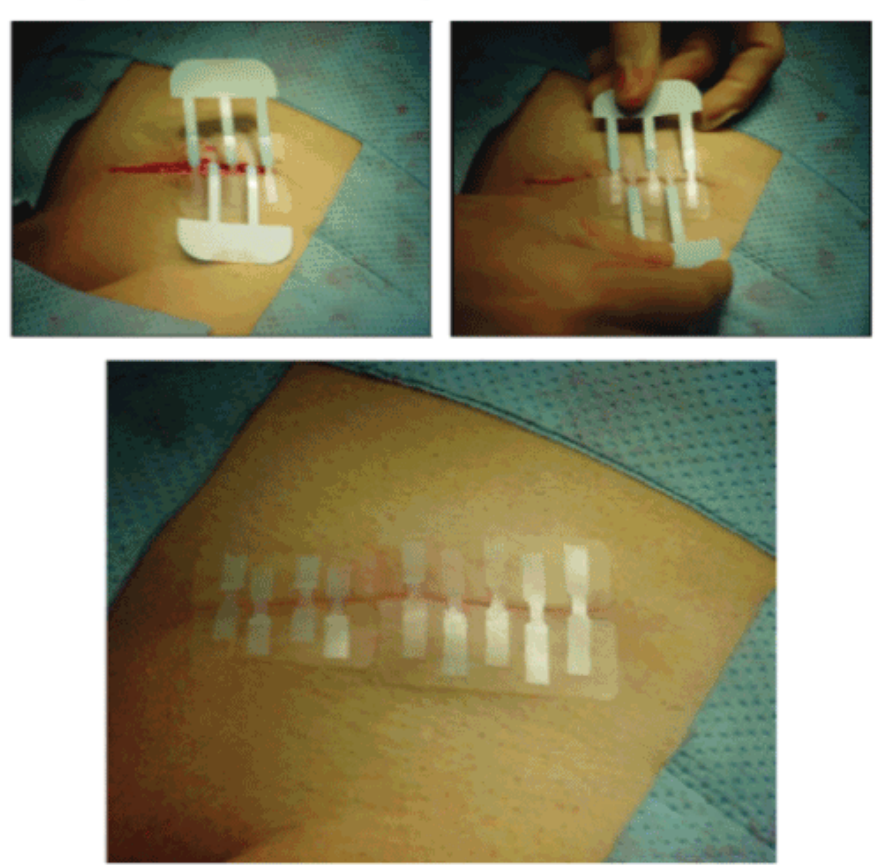

Figure 2. The Cloze $\mathrm{X}^{\circledR}$ System provides Equal Tension Across the Surgical Wound ${ }^{\mathrm{a}}$ ${ }^{\mathrm{a} C l o z e X}{ }^{\circledR}$ Medical Inc, Wellesley, MA

demonstrated improved cosmesis, reduced healing time, and shorter operative time when compared to traditional alternatives [22,23]. However, cutaneous complications, such as severe allergic dermatitis, have been linked to its use [24,25]. Huemer et al. [22] reported 4 cases of contact dermatitis, and postulate this may be due to prior exposure as each patient had previously used this device. Parvizi et al. [23] suggest that the Prineo system should not be used in patients with known or suspected sensitivity to cyanoacrylate, formaldehyde, or adhesives. It is also recommended that tissue adhesives not be used to close contaminated or infected wounds, and should be avoided in areas prone to frequent moisture or friction, such as the hands and feet [26]. In addition, the cost of adhesives may be up to 4 times as expensive as sutures, and they require a meticulous technique to ensure no gaps or bleeding exist between wound edges [27].

Another alternative to conventional sutures is the Zip 16 Surgical Skin Closure System, an adjustable and reversible skin closure device. Patients have reported less pain during removal when compared to staples [28] or sutures, [29] and fewer wound complications have been reported [30]. The existing literature regarding this technology has been positive, with adverse events being, at worst, similar to those of conventional methods [30-32]. It is unknown whether the incidence of surgical site infection is lower with the closure device compared to alternative methods,[33] however, and whether holding strength is different from that of staples [34].

The ClozeX system has been shown to be an improvement on conventional wound closure methods (Figures 3-5). In a study comparing coaptive film and monocryl sutures in pediatric spine surgery, Grottkau et al. [35] found that using ClozeX resulted in a mean of 384.13 seconds shorter closure time $(p<0.01)$, and no difference in cosmetic score. Shorter closure time, improved aesthetics, less inflammation, and similar rates of dehiscence, pain, and infection have also been reported [36-40]. 
${ }^{\mathrm{a}} \mathrm{ClozeX}^{\circledR}$ Medical Inc, Wellesley, MA
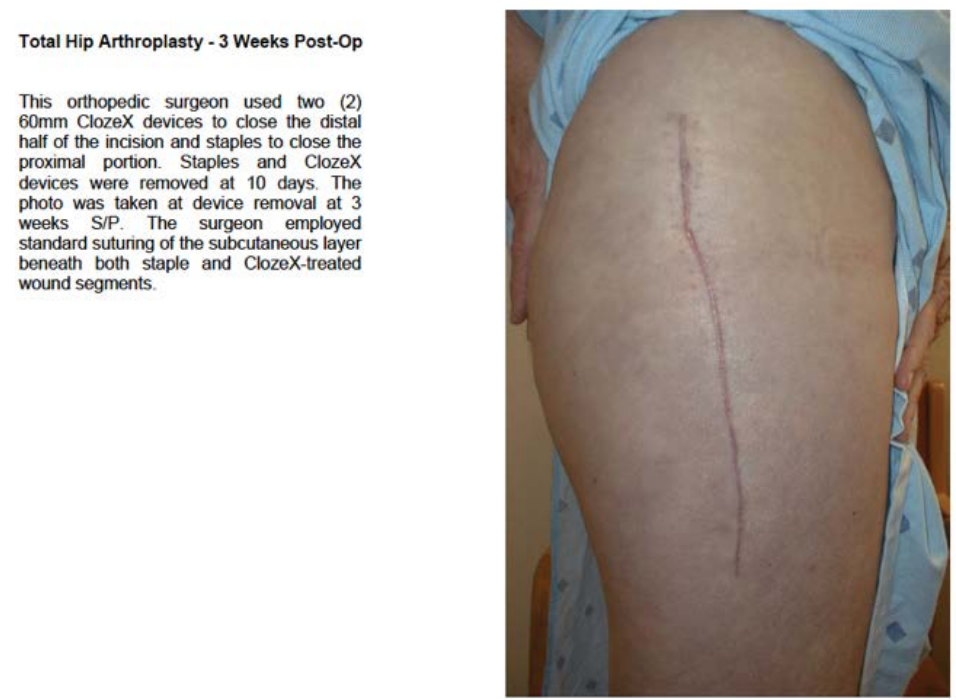

Figure 3. Healing Surgical Wound after Cloze ${ }^{\circledR}$ Application in Hip Surgery ${ }^{\mathrm{a}}$
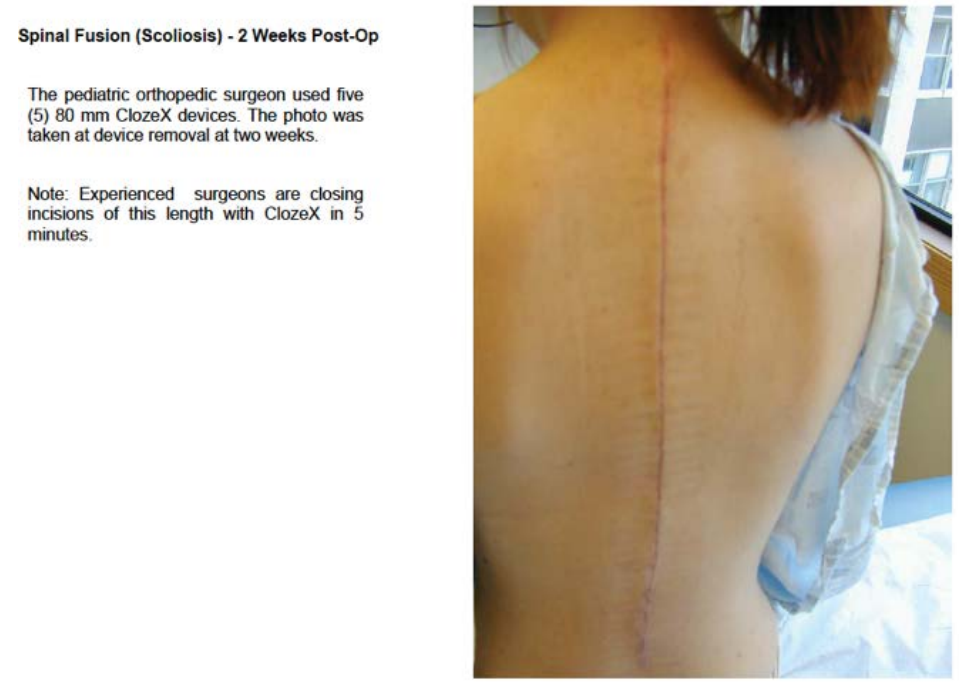

Figure 4. Healing Surgical Wound after ClozeX ${ }^{\circledR}$ Application in Spine Surgery a

${ }^{\text {a }}$ ClozeX ${ }^{\circledR}$ Medical LLC, Wellesley, MA

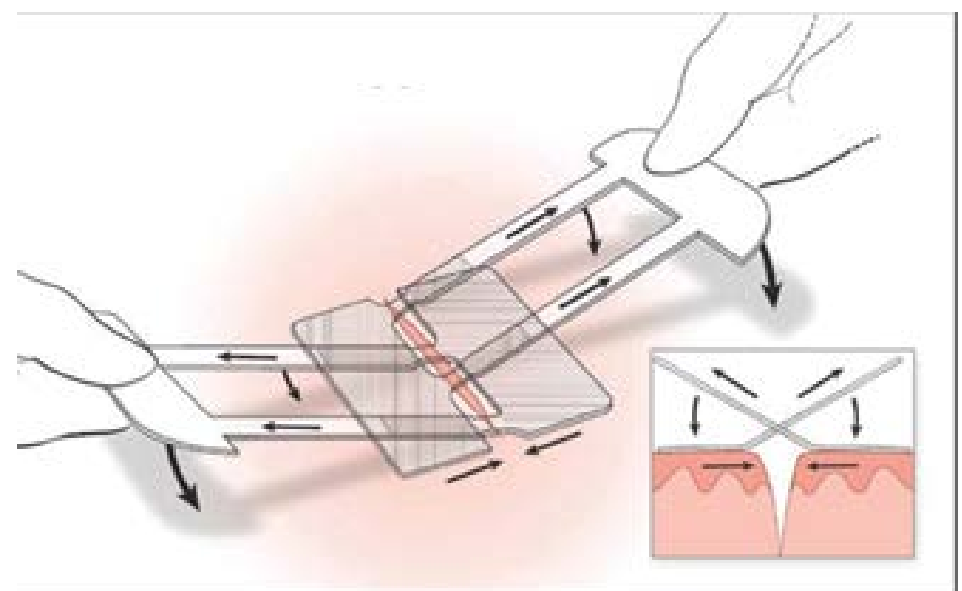

Figure 5. Clozex Closure Application 
ClozeX $^{\circ}$ also appears to be a more cost-effective closure method. Rebello et al. [19] found that estimated operating room cost is about $\$ 2,250$ for 30 minutes, which translates to savings of greater than $\$ 550$ if the ClozeX system is used due to its fast and efficient application. Overall cost savings are estimated to be $\$ 964$, based on these data [19]. In a study by Shippert [41], the average per-minute operating room fee in the United States was \$ 66 in 2005. However, fees charged to patients usually do not reflect the actual costs. According to an editorial by Macario [42], some operating room administrators consider a ballpark "true cost" of operating room time to be approximately $\$ 15$ to $\$ 20$ per minute for a basic surgical procedure. With this novel wound closure device, shorter operating times, low complication rates, and no need for follow up visits to remove sutures translate to considerable cost savings.

\section{Conclusion}

The ClozeX" technique shows promise to not only improve the postoperative appearance of a wound, but also a cost-effective alternative to enhance wound closure. It reduces operative time, lowers the rate of surgical site infections, and produces similar or superior outcomes to those of staples and skin adhesives. This ClozeX system provides a reasonable alternative to conventional and other novel wound closure devices. This device may be of special use in high risk wounds where a post-operative wound vacuum dressing is being considered. The ClozeX device would allow not only a cosmetic and efficacious closure, but would not hamper the potential positive effects of wound vac therapy.

\section{References}

1. Vince K, Chivas D, Droll KP (2007) Wound complications after total knee arthroplasty. J Arthroplasty 22: 39-44. [Crossref]

2. Surin VV, Sundholm K, Bäckman L (1983) Infection after total hip replacement. With special reference to a discharge from the wound. J Bone Joint Surg Br 65: 412-418. [Crossref]

3. Galat DD, McGovern SC, Larson DR, Harrington JR, Hanssen AD (2009) Surgical treatment of early wound complications following primary total knee arthroplasty. $J$ Bone Joint Surg Am 91: 48-54. [Crossref]

4. Wagenaar FBM, Löwik CAM, Zahar A, Jutte PC, Gehrke T, et al. (2018) Persistent Wound Drainage After Total Joint Arthroplasty: A Narrative Review. J Arthroplasty pii: S0883-5403(18)30738-1. [Crossref]

5. Adelani MA, Johnson SR, Keeney JA, Nunley RM, Barrack RL (2014) Clinical outcomes following re-admission for non-infectious wound complications after primary total knee replacement. Bone Joint J 96: 619-621.

6. Hansen E, Durinka JB, Costanzo JA, Austin MS, Deirmengian G (2013) Negative pressure wound therapy is associated with resolution of incisional drainage in most wounds after hip arthroplasty. Clin Orthop Relat Res 471: 3230-3236. [Crossref]

7. Gililland JM, Anderson AL, Barney JK, Ross HL, Pelt CE, Peters CL (2014) Barbed versus standard sutures for closure in total knee arthroplasty: a multicenter prospective randomized trial. J Arthroplast 29: 135-138. [Crossref]

8. Nett M, Avelar R, Sheehan M, Cushner F (2011) Water-tight knee arthrotomy closure: comparison of a novel single bidirectional barbed self-retaining running suture versus conventional interrupted sutures. J Knee Surg 24: 55-59. [Crossref]

9. Chen J, Xie CL, Xuan J, Yan YZ, Dou HC, et al. (2018) A Novel Knotless Barbed Suture Technique for Traumatic Thoracolumbar Fracture in Posterior Surgery. World Neurosurg 14: e1031-e1037. [Crossref]

10. Gililland JM, Anderson LA, Barney JK, Ross HL, Pelt CE, et al. (2014) Barbed versus standard sutures for closure in total knee arthroplasty: a multicenter prospective randomized trial. J Arthroplast 29: 135-138 [Crossref]

11. Meena S, Gangary S, Sharma P, Chowdhury B (2015) Barbed versus standard sutures in total knee arthroplasty: a meta-analysis. Eur J Orthop Surg Traumatol 25: 11051110. [Crossref]

12. Shermak MA, Mallalieu J, Chang D (2010) Barbed suture impact on wound closure in body contouring surgery. Plast Reconstr Surg 126: 1735-1741. [Crossref]
13. Campbell AL, Patrick DA Jr, Liabaud B, Geller JA (2014) Superficial wound closure complications with barbed sutures following knee arthroplasty. J Arthroplasty 29: 966969. [Crossref]

14. Krishnan R, MacNeil SD, Malvankar-Mehta MS (2016) Comparing sutures versus staples for skin closure after orthopaedic surgery: systematic review and meta-analysis. BMJ Open 6: e009257.

15. Iavazzo C, Gkegkes ID, Vouloumanou EK, Mamais I, Peppas G, et al. (2011) Sutures versus staples for the management of surgical wounds: a meta-analysis of randomized controlled trials. Am Surg 77: 1206-1221. [Crossref]

16. Kuroki LM, Mullen MM, Massad LS, Wu N, Liu J, et al. (2017) Wound Complication Rates After Staples or Suture for Midline Vertical Skin Closure in Obese Women: A Randomized Controlled Trial. Obstet Gynecol 130: 91-99. [Crossref]

17. Ando M, Tamaki T, Yoshida M, Sasaki S, Toge Y, et al. (2014) Surgical site infection in spinal surgery: a comparative study between 2-octyl-cyanoacrylate and staples for wound closure. Eur Spine J 23: 854-862. [Crossref]

18. Smith TO, Sexton D, Mann C, Donell S (2010) Sutures versus staples for skin closure in orthopaedic surgery: meta-analysis. BMJ 340: c1199. [Crossref]

19. Clozex Medical Inc (2018) CLOZEX: The Next Generation of Wound Closure Improves Safety, Speed and Satisfaction. 1-9.

20. Daykan Y, Sharon-Weiner M, Pasternak Y, Tzadikevitch-Geffen K, Markovitch O, et al. (2017) Skin closure at cesarean delivery, glue vs subcuticular sutures: a randomized controlled trial. Am J Obstet Gynecol 216: 406.e1-406.e5. [Crossref]

21. Martin JG, Hollenbeck ST, Janas G, Makar RA, Pabon-Ramos WM, et al. (2017) Randomized Controlled Trial of Octyl Cyanoacrylate Skin Adhesive versus Subcuticular Suture for Skin Closure after Implantable Venous Port Placement. J Vasc Interv Radiol 28: 111-116. [Crossref]

22. Huemer GM, Schmidt M, Helml GH, Shafighi M, Dunst-Huemer KM (2012) Effective wound closure with a new two-component wound closure device $\left(\mathrm{Prineo}^{\mathrm{TM}}\right)$ in excisional body-contouring surgery: experience in over 200 procedures. Aesthetic Plast Surg 36: 382-386. [Crossref]

23. Parvizi D, Friedl H, Schintler MV, Rappl T, Laback C, et al. (2013) Use of 2-octyl cyanoacrylate together with a self-adhering mesh (Dermabond ${ }^{\mathrm{TM}}$ Prineo ${ }^{\mathrm{TM}}$ ) for skin closure following abdominoplasty: an open, prospective, controlled, randomized, clinical study. Aesthetic Plast Surg 37: 529-537. [Crossref]

24. Davis MD, Stuart MJ (2016) Severe allergic contact dermatitis to dermabond prineo, a topical skin adhesive of 2-octyl cyanoacrylate increasingly used in surgeries to close wounds. Dermatitis 27: 75-76. [Crossref]

25. Caton AM, Dauphine C (2004) Allergic contact dermatitis after repeated exposure to dermabond. Am Surg 80: 520-522. [Crossref]

26. Singer AJ, Thode HC (2004) A review of the literature on octylcyanoacrylate tissue adhesive. Am J Surg 187: 238-248. [Crossref]

27. Knott PD, Zins JE, Banbury J, Djohan R, Yetman RJ, et al. (2007) A comparison of dermabond tissue adhesive and sutures in the primary repair of the congenital cleft lip. Ann Plast Surg 58: 121-125. [Crossref]

28. Ko JH, Yang IH, Ko MS, Kamolhuja E, Park KK (2017) Do zip-type skin-closing devices show better wound status compared to conventional staple devices in total knee arthroplasty? Int Wound J 14: 250-254. [Crossref]

29. Tanaka Y, Miyamoto T, Naito Y, Yoshitake S, Sasahara A, et al. (2016) Randomized Study of a New Noninvasive Skin Closure Device for Use After Congenital Heart Operations. Ann Thorac Surg 102: 1368-1374. [Crossref]

30. Carli AV, Spiro S, Barlow BT, Haas SB (2017) Using a non-invasive secure skin closure following total knee arthroplasty leads to fewer wound complications and no patient home care visits compared to surgical staples. Knee 24: 1221-1226. [Crossref]

31. Mitwalli H, Dolan C, Bacigalupi R, Khorasani H (2016) A randomized, controlled, prospective clinical study comparing a novel skin closure device to conventional suturing. J Am Acad Dermatol74: 173-174. [Crossref]

32. Chen D, Song J, Zhao Y, Zheng X, Yu A (2016) Systematic Review and Meta-Analysis of Surgical Zipper Technique versus Intracutaneous Sutures for the Closing of Surgical Incision. PLoS One 11: e0162471. [Crossref]

33. Binkley M, Albrecht MJ, Srikumaran U (2017) Noninvasive device helps with elective, traumatic shoulder incision closure. Healio Orthopedics today.

34. Levi K, Ichiryu K, Kefel P, Keller J, Grice J, et al. (2016) Mechanics of Wound Closure: Emerging Tape-Based Wound Closure Technology vs. Traditional Methods. Cureus 8: e827. [Crossref] 
35. Grottkau BE, Rebello G, Merlin G, Winograd JM (2010) Coaptive film versus subcuticular suture: comparing skin closure time after posterior spinal instrumented fusion in Pediatric patients with spinal deformity. Spine 35: 2027-2029. [Crossref]

36. Rebello G, Parikh R, Grottaku B (2009) Coaptive film versus subcuticular suture: comparing skin closure time following identical, single-session, bilateral limb surgery in children. J Pediatr Orthop 29: 626-628. [Crossref]

37. Anuar Ramdhan I, Zulmi W, Hidayah A, Kamel M, Fadhil M, et al. (2013) Comparative study between coaptive film versus suture for wound closure after long bonefracture fixation. Malays Orthop J 7: 52-55. [Crossref]

38. Lazar HL, McCann J, Fitzgerald CA, Cabral HJ (2011) Adhesive strips versus subcuticular suture for median sternotomy wound closure. J Card Surg 26: 344-347. [Crossref]

39. Kuo F, Lee D, Roger GS (2006) Prospective, randomized, blinded study of a new wound closure film versus cutaneous suture for surgical wound closure. Dermatol Surg 32: 676-681. [Crossref]

40. Kerrigan CL, Homa K (2010) Evaluation of a new wound closure device for linear surgical incisions: 3M Steri-Strip S Surgical Skin Closure versus subcuticular closure. Plast Reconstr Surg 125:186-194. [Crossref]

41. Shippert RD (2005) A Study of Time-Dependent Operating Room Fees and How to save $\$ 100000$ by Using Time-Saving Products. American Journal of Cosmetic Surgery 22: 25-34
42. Macario A, Dexter F, Traub RD (2001) Hospital profitability per hour of operating room time can vary among surgeons. Anesth Analg 93: 669-675. [Crossref]

43. Bruns TB, Worthington JM (2000) Using tissue adhesive for wound repair: a practical guide to dermabond. Am Fam Physician 61: 1383-1388. [Crossref]

44. Zhang W, Xue D, Yin H, Xie H, Ma H, et al. (2016) Barbed versus traditional sutures for wound closure in knee arthroplasty: a systematic review and meta-analysis. Sci Rep 6: 19764. [Crossref]

45. Ong J, Ho KS, Chew MH, Eu KW (2010) Prospective randomised study to evaluate the use of DERMABOND ProPen (2-octylcyanoacrylate) in the closure of abdominal wounds versus closure with skin staples in patients undergoing elective colectomy. Int J Colorectal Dis 25: 899-905. [Crossref]

46. Al-Mubarak L, Al-Haddab M (2013) Cutaneous wound closure materials: an overview and update. J Cutan Aesthet Surg 6: 178-188. [Crossref]

47. Glennie RA, Korczak A, Naudie DD, Bryant DM, Howard JL (2017) MONOCRYL and DERMABOND vs Staples in Total Hip Arthroplasty Performed Through a Lateral Skin Incision: A Randomized Controlled Trial Using a Patient-Cantered Assessment Tool. J Arthroplasty 32: 2431-2435. [Crossref]

Copyright: (C2018 Congiusta D. This is an open-access article distributed under the terms of the Creative Commons Attribution License, which permits unrestricted use, distribution, and reproduction in any medium, provided the original author and source are credited. 